\title{
Pemodelan Time Series Multivariat secara Automatis
}

\author{
Siana Halim ${ }^{1}$, Arif Chandra ${ }^{1}$
}

\begin{abstract}
We constructed an automatic multivariate time series algorithm and implemented that algorithm into R-package. Four instruments in used are vector auto regressive (VAR), structural vector auto regressive (SVAR), vector error correction model (VECM), and structural vector error correction (SVEC). VAR and VECM are employed to estimate and construct models and, subsequently, predict the future values of an object. SVAR and SVEC serve to analyze innovative structures of a model. VAR and SVAR can be implemented only to stationary data whilst VECM and SVEC can be applied to non-stationary inputs. Based on this package, all the aforestated models are conclusively able to identify dynamic relationship of endogenous variabel in a model well.
\end{abstract}

Keywords: Multivariate time series, VAR, SVAR, VECM, SVEC

\section{Pendahuluan}

Telah umum diketahui bahwa nilai suatu peramalan (forecasting) merupakan landasan untuk menentukan keputusan untuk berproduksi ataupun berinvestasi (Hadi [4]). Tak heran, saat ini ada berbagai macam perangkat lunak (software) yang menawarkan kemudahan untuk melakukan peramalan ini. Diantaranya adalah, Eviews, Minitab, SPSS. Namun demikian, perangkat lunak ini menuntut adanya pengetahuan statistika yang kuat dari para penggunanya agar mereka mendapatkan hasil peramalan yang dapat dipercayai. Adanya keterbatasan yang tersebut, memberikan ide untuk membuat suatu perangkat lunak yang memberikan hasil peramalan secara automatis, sehingga seseorang tanpa pengetahuan statistika yang dalam, terutama dibidang analisa ataupun financial time series mampu mengoperasikannya.

Nilai peramalan pada sebuah objek seringkali tidak hanya dipengaruhi oleh sebuah time series saja, namun dapat tergantung pada time series lainnya. Untuk itulah, pada penelitian ini akan dibangun sebuah automatic multivariate forecasting $R$ package. Pemodelan time series multivariat dilakukan dengan menggunakan pendekatan ekonometrik. Sims [9] mengembangkan vector auto regressive (VAR), yang merupakan model peramalan time series multivariat yang paling sering digunakan untuk memprediksi data stasioner. VAR kemudian mengalami perkembangan sehingga mampu membangun vector error

\footnotetext{
1 Fakultas Teknologi Industri, Jurusan Teknik Industri, Universitas Kristen Petra. Jl. Siwalankerto 121-131, Surabaya 60236, Indonesia, Email: halim@petra.ac.id,
}

Diterima 18 November 2010; revised1 5 Mei 2011; Accepted 20 Mei 2011. correction model (VECM) dan structural vector error correction (SVEC) yang digunakan untuk menginterpretasi hubungan kontemporer variabel. Model ini dinamakan dengan structural vector auto regressive (SVAR). Pada waktu yang hampir bersamaan, Granger [3] menemukan konsep kointegrasi yang mencari relasi linear antar variabel pada data non-stasioner. Konsep ini selanjutnya digunakan untuk menginterpretasi hubungan kontemporer variabel.

Data sebelum dimodelkan akan mengalami identifikasi awal, kemudian berlanjut ke estimasi parameter, analisis struktural, dan diagnostic checking. Estimasi parameter terbaik untuk masing-masing model dilakukan dengan menggunakan nilai maximum log-likelihood yang meminimalkan hasil residual. Model terbaik akan digunakan untuk memprediksi nilai masa mendatang. Pembentukan model akan dibangun menggunakan software $\mathrm{R}$ 2.11.2, yang merupakan kelanjutan dari package peramalan time series univariat secara automatis (Halim, et al. [5])

\section{Metodologi Penelitian}

Pemodelan package time series multivariat secara automatis ini, merupakan kelanjutan dari package serupa namun untuk time series univariat (Halim et al. [5]). Pada dasarnya adaptasi yang dilakukan tidak jauh berbeda. Paparan dari adaptasi tersebut dapat diikuti pada bagian ini.

Pada awalnya, stasioneritas data yang diinputkan ke dalam package akan diuji menggunakan Automatic Dickey Fuller (ADF) test (Harris dan Sallis [6]) untuk setiap peubah. Sebuah data dikatakan stasioner jika mean, varian, covariance dari time series konstan untuk semua periode dan tidak mem- 
punyai fluktuasi periodik. Kestasioneran sebuah data dapat dilihat dari perilaku autocorrelation function (ACF) atau partial autocorrelation function (PACF) data tersebut. Selanjutnya jika data tersebut stasioner, maka data tersebut akan dimodel dengan menggunakan VAR yang dapat diperbaiki lagi dengan SVAR. Namun bila data tersebut tidak stasioner, maka nonstasioner modelah yang akan digunakan untuk memodelkannya. Adapun nonstationer model yang akan digunakan adalah VECM ataupun SVEC.

Resume dari beberapa teori yang akan digunakan dalam pemodelan tersebut di atas akan disampaikan pada sub bagian berikut. Detail dari penjelasan ini dapat dilihat di Luetkepohl [7], Brooks [2].

\section{Time Series Multivariat}

Time series multivariate memodelkan peubahpeubah yang berkorelasi dan tercatat dari waktu ke waktu. Peubah tersebut dinotasikan sebagai berikut $y_{1 t}, y_{2, t}, \ldots, y_{N, t}$; dimana $y_{i t}, i=1, \ldots, N$ adalah peubah ke- $i$ yang dicatat pada saat $t$. Prediksi pada peubah $N$ pada saat $T+h$ dapat dituliskan sebagai fungsi berikut

$\hat{y}_{N, T+h}=f_{N}\left(y_{1, T}, \ldots, y_{N, T}, y_{1, T-1}, \ldots, y_{N, T-1}\right)$

Tujuan utama dari pemodelan time series multivariat adalah menentukan estimasi fungsi yang tepat sehingga fungsi tersebut dapat digunakan untuk memprediksi nilai mendatang (future value) dengan baik; untuk semua peubah di dalam sistem.

\section{Model untuk Data Stasioner}

Model untuk data multivariat stasioner yang akan diulas pada bagian ini adalah Vector Auto Regressive (VAR) dan Struktural Vector Auto Regressive (SVAR).

\section{Vector Auto Regressive Model}

Model VAR dapat menjelaskan peubah endogen dari data masa lalu peubah tersebut dan peubah endogen lainnya. Model $\operatorname{VAR}(p) ; p$ adalah orde dari model, dapat ditulis:

$$
\begin{gathered}
\begin{array}{c}
\hat{y}_{n, T+h}=v+\alpha_{n 1,1} y_{1, T}+\alpha_{n 2,1} y_{2, T}+\cdots+\alpha_{n N, 1} y_{N, T} \\
\quad+\alpha_{n 1, p} y_{1, T-p+1}+\cdots+\alpha_{n N, p} y_{N, T-p+1}
\end{array} \\
n=1, \ldots, N
\end{gathered}
$$

dimana $\alpha_{n 1,1}, \ldots, \alpha_{n N, p}$ adalah parameter koefisien yang harus diestimasi.

Secara umum, penulisan persamaan (2) dapat dibentuk menjadi:

$y_{t}=v+A_{1} y_{t-1}+\cdots+A_{p} y_{t-p}+u_{t}, t=0, \pm 1, \pm 2, \ldots$ dengan $y_{t}=\left(y_{1, t}, \ldots, y_{N, t}\right)^{\prime}$, transpose dari vektor peubah; $A_{i}, i=1, \ldots, p$ adalah koefisien matriks berukuran $(K \times K)$ dan $u_{t}$ adalah proses berdimensi $K$, dengan $\mathbb{E}\left(u_{t}\right)=0$ dan memiliki matriks kovarians $\mathbb{E}\left(u_{t} u_{t}\right)^{\prime}=\Sigma_{u}$ definit positif (white noise). Ada dua hal utama yang harus diestimasi pada model di atas, yaitu $p$ yang dapat menunjukkan model terbaik dan tentu saja matriks koefisien $A_{i}, i=$ $1, \ldots, p$. Kriteria pemilihan orde terbaik dijelaskan secara singkat di bawah ini, sedangkan estimasi matriks koefisien $A_{i}, i=1, \ldots, p$ dapat dilihat secara detail pada Luetkepohl [7].

\section{Pemilihan Orde Vector Auto Regressive}

Pada package ini digunakan empat kriteria untuk memilih orde $(p)$ terbaik, yaitu: Final Prediction Error (FPE), Akaike Information Criterion (AIC), Hannan-Quinn Criterion (HQ), Schwarz Information Criterion (SIC). Seperti halnya pada time series univariat, alat (tool) yang digunakan untuk menentukan nilai $p$ adalah partial auto corelation function (PACF).

Setelah mendapatkan orde $p$ terbaik, maka model $\operatorname{VAR}(p)$ yang terbentuk perlu diagnosa terhadap persyaratan stabilitas dan normalitas. Stabilitas di dalam model VAR diperlukan, sebagaimana dengan uji stasioneritas pada model AR. Stabilitas ini adalah uji stasioneritas secara bersama-sama pada peubah multivariat.

\section{Stability dan Normality Condition}

Suatu model dikatakan stabil jika memenuhi persamaan:

$\operatorname{det}\left(I_{N}-A_{1} y-\cdots-A_{p} y^{p}\right) \neq 0,|y| \leq 1$

Stabilitas terjadi jika reverse characteristic polynomial dari model tidak mempunyai roots di dalam dan pada unit circle (semua nilai eigen $<1$ ). Kondisi normalitas pada data diuji dengan menggunakan Jarque-Bera test.

$J B=N / 6\left(S^{2}+1 / 4 K^{4}\right)$

dengan $\mathrm{N}$ adalah jumlah observasi, $S$ dan $K$ adalah sampel skewness dan kurtosis secara berturutan. Statistik $J B$ asimptotik terhadap distribusi chisquare dengan dua derajat kebebasan (degree of freedom).

Jika data tidak memenuhi kedua persyaratan pertama ini maka package akan memberikan peringatan dan menghentikan proses. Namun, bila kedua syarat tersebut terpenuhi, maka akan dilakukan analisa struktural terhadap VAR. 


\section{Analisis Struktural terhadap VAR}

Uji struktural diperlukan untuk mengetahui hubungan kausalitas (saling memberikan pengaruh) antar peubah. Digunakan Granger-causality test untuk menguji kausalitas pada data (Granger [3]). Bila syarat kausalitas ini terpenuhi maka pemilihan model VAR terbaik dapat dilakukan, namun bila tidak maka sekali lagi package akan memberikan peringatan dan proses pemodelan berhenti.

Uji diagnostik terhadap model terbaik beserta analisa terhadap impulse response function (IRF) dan Forecast Error Variance decomposition (FEVD) selanjutnya dilakukan terhadap model terpilih.

Kelemahan model VAR adalah tidak mampu menangkap adanya pergerakan deterministik data time series. Oleh karena itu, Stuctural Vector Auto Regressive (SVAR) dibangun untuk menganalisis pergerakan deterministik model VAR.

\section{Structural Vector Auto Regressive Model}

Model SVAR dapat dituliskan

$A y_{t}=A_{1}^{*} y_{t-1}+\cdots+A_{p}^{*} y_{t-p}+B U_{t}, t=0, \pm 1, \pm 2, \ldots$

Dua tipe SVAR yang dapat diestimasi dengan adanya penambahan pembatas pada matriks $A$ atau $B$ adalah (a) Model A: $B$ didefinisikan sebagai $I_{N}$, (b) Model B: $A$ didefinisikan sebagai $I_{N}$ dengan minimum jumlah pembatas untuk identifikasi model $\mathrm{A}$ dan B adalah $N(N-1) / 2$.

Langkah selanjutnya adalah sama, yaitu menentukan model SVAR terbaik dan uji diagnostik. Bila semua uji tersebut dapat terpenuhi maka package akan menyajikan model terbaik. Selain itu, package juga memberikan prediksi $h$ lag ke depan sesuai permintaan pengguna, beserta dengan 95\% interval keyakinan (default namun dapat diubah). Rangkaian ini mengakhiri pemodelan time series multivariat secara automatis untuk data stationer. Pada subbab berikut akan dipaparkan pemodelan serupa namun untuk data non-stasioner.

\section{Model untuk Data Nonstasioner}

Pada data multivariat, nonstasioneritas dapat terjadi pada semua peubah atau hanya pada sebagian saja dari peubah yang ada. Bila peubah tersebut seluruhnya nonstasioner, maka pemodelan dapat ditanggani dengan model-model Vector Error Correction (VEC) ataupun Structural Vector Error Correction (SVEC). Namun bila hanya sebagian saja dari peubah tersebut yang stasioner, terdapat dua pilihan untuk memodelkan peubah seperti ini.
Kedua pilihan tersebut adalah pertama, memodelkan terlebih dahulu gabungan peubah stasioner dan non stationer ke dalam model VAR, SVAR kemudian dilanjutkan dengan model VEC dan SVEC. Tentu saja prosedur ini akan memakan waktu lebih lama, namun diyakini lebih tangguh serta memberikan model yang lebih baik. Pilihan kedua adalah memodelkan gabungan tersebut secara langsung ke dalam model VECM dan SVEC.

Kedua pilihan ini disediakan oleh package time series multivariat.

Pada data nonstasioner diperlukan uji kointegrasi antar peubah-peubahnya. Uji kointegrasi dilakukan dengan menggunakan prosedur Johannsen (Harris and Sallis, [6]). Bila peubah-peubah dalam data tidak berkointegrasi, maka package akan memberkan peringatan dan pemodelan berhenti. Namun, bila persyaratan ini terpenuhi pemodelan dengan VECM dapat dilakukan.

\section{Vector Error Correction Model}

Vector error correction model adalah model untuk menganalisis data multivariate time series yang tidak stasioner. Model VAR yang memiliki hubungan kointegrasi secara linear akan berubah menjadi model VECM, yaitu:

$$
\begin{aligned}
& \Delta y_{t}=\alpha \beta^{T} y_{t-1}+\Gamma_{1} \Delta y_{t-1}+\cdots+\Gamma_{p-1} \Delta y_{t-p+1}+U_{t} \\
& \Gamma_{i}=-\left(I-A_{1}-\cdots-A_{i}\right)
\end{aligned}
$$

Parameter $\alpha$ dan $\beta$ mempunyai dimensi $N \mathrm{x} r$, ( $N$ : jumlah peubah dan $r$ : derajat kointegrasi). Derajat kointegrasi menunjukkan berapa panjang hubungan jangka panjang di antara peubah $y_{t}$ dari model. Salah satu syarat agar model VECM dapat dibangun selain model tidak stasioner adalah terkointegrasi. Granger [3] mendefinisikan koin-tegrasi dengan masuknya vector $\beta$ ke dalam sebuah persamaan regresi $\left(y_{t}=\mu_{t}+\beta x_{t}\right)$. Sedangkan derajat kointegrasi ditentukan dengan menggunakan Johansen procedure.

Diagnostik tes dan uji yang lain seperti halnya pada model stasioner akan dilakukan pada bagian ini, sebelum model SVEC dibentuk.

\section{Structural Vector Error Correction Model}

Model SVEC dibangun dikarenakan informasi yang terdapat di dalam properti kointegrasi dari peubah tidak mengidentifikasi restrictions (batasan) pada structural shock. Pada SVEC ini diasumsikan model B yang akan digunakan. Model SVEC dapat dituliskan sebagai berikut: 
$\Delta y_{t}=\alpha \beta^{T} y_{t-1}+\Gamma_{1} \Delta y_{t-1}+\cdots+\Gamma_{p-1} \Delta y_{t-p+1}+B \varepsilon_{t}$ $\varepsilon_{t} \sim \mathcal{N}\left(0, I_{N}\right) ; \Delta \mathrm{y}_{\mathrm{t}}=\mathrm{y}_{\mathrm{t}}-\mathrm{y}_{\mathrm{t}-1}$

$\Gamma_{i}=-\left(I-A_{1}-\cdots-A_{i}\right)$

Pada model SVEC diperlukan batasan sebanyak $N(N-1) / 2)$.

Pada akhir dari pemodelan ini IRF dan FEVD akan dianalisa, dan laporan hasil akhir beserta model terbaik baik itu stasioner ataupun non stasioner akan diberikan pada pengguna. Alur pemodelan time series multivariat secara lengkap dapat dilihat pada Gambar 1.

Resume tentang impulse response dan variance decomposition diulas di bagian akhir dari metodologi penelitian ini, agar tidak menganggu bagan utama pada pemodelan time series multivariat.

\section{Inovasi dalam Model Time Series Multivariat Impulse Response}

Impulse response dipahami sebagai fungsi dinamis untuk melacak pengaruh suatu shock yang terjadi terhadap peubah endogen di dalam sistem. Impulse response berfungsi untuk mencari reaksi dari peubah dependen di dalam model VAR, SVAR, VECM, ataupun SVEC terhadap shock untuk setiap peubah di dalam model tersebut. Shock yang terjadi pada peubah ke- $i$ tidak hanya secara langsung berdampak pada nilai peubah ke- $i$ tersebut, namun juga mengakibatkan pengaruh kepada semua peubah endogen yang ada dalam struktur dinamis model.

\section{Variance Decomposition}

Variance decomposition bertujuan memisahkan dampak masing-masing shock secara individual terhadap respon yang diterima sebuah peubah. Metode ini akan memberikan proporsi terhadap pergerakan di dalam peubah dependen yang berhubungan langsung dengan shock pada peubah itu sendiri, dan juga terhadap shock lain pada peubah lainnya. Sebuah shock terhadap peubah ke- $i$ selain secara langsung mempengaruhi peubah itu sendiri, maka shock tersebut juga akan mempengaruhi semua peubah di dalam struktur dinamis model VAR yang dibangun.

\section{Hasil dan Pembahasan}

\section{Deskripsi Data}

Data yang digunakan adalah data Canada (Pfaff [8]). Data Canada berisi empat peubah sebagai indikasi perekonomian Canada dari tahun 1980 kuarter pertama hingga tahun 2000 kuarter keempat. Keempat peubah tersebut adalah $e$ (log employ- ment), prod (log produktifitas buruh yang didefinisikan sebagai logaritma dari selisih antara GDP dan employment), rw (real wage index - upah sesungguhnya), dan U(Unemployment - pengangguran).

Langkah selanjutnya adalah melakukan uji kestasioneran data dengan ADF-test. ADF-test dibagi menjadi 2 bagian, yaitu tes dengan melibatkan kondisi musiman dan tes yang tidak melibatkan kondisi musiman. ADF-test untuk kondisi musiman menyatakan bahwa data Canada tidak mengandung kondisi musiman (seasonal). Pada versi ini pengujian seasonalitas hanya dilakukan untuk musim 3 (per kuartal), 6 (per setengah tahun), dan 12 (per tahun) saja. Namun, pengguna juga bisa mencoba untuk memasukkan data seasonal lain yang diduganya. Hal ini akan diperbaiki untuk versi selanjutnya agar package dapat menjadi automatik penuh. Peubah $e$ dan prod menunjukkan kondisi tidak stasioner dengan trend dan drift, sedangkan peubah $r w$ dan $U$ menghasilkan keputusan bahwa kedua peubah tersebut stasioner. ADF-test yang langsung menguji kestasioneran dari peubah tanpa melihat apakah peubah mengandung musiman atau tidak menunjukkan bahwa keempat peubah tidak ada yang stasioner.

\section{Analisis VAR}

Data yang dimodelkan terlebih dahulu harus mengalami pemilihan lag, stability check, uji kenormalan model, dan identifikasi Granger-causality. Lag awal yang dipilih adalah 10 dan setelah mengalami serangkaian analisis, maka didapatkan lag terbaik adalah 3 dengan tipe both. Nilai log-likelihood model adalah -143,6292. Cek diagnostik untuk model dilakukan dengan histogram residual, uji normal untuk residual, plot ACF, dan plot PACF. Semua hasil menunjukkan bahwa model layak digunakan dalam meramalkan nilai masa mendatang.

Hasil model VAR dapat dituliskan sebagai berikut:

$$
\left[\begin{array}{c}
e_{t} \\
\operatorname{prod}_{t} \\
r w_{t} \\
U_{t}
\end{array}\right]=A_{1}\left[\begin{array}{c}
e_{t-1} \\
\operatorname{rrod}_{t-1} \\
r w_{t-1} \\
U_{t-1}
\end{array}\right]+A_{2}\left[\begin{array}{c}
e_{t-2} \\
\operatorname{prod}_{t-2} \\
r w_{t-2} \\
U_{t-2}
\end{array}\right]+A_{3}\left[\begin{array}{c}
e_{t-3} \\
\operatorname{prod}_{t-3} \\
r w_{t-3} \\
U_{t-3}
\end{array}\right]+
$$$$
\text { const }+ \text { trend }
$$

dimana

$$
\begin{aligned}
& A_{1}=\left[\begin{array}{rrrr}
1,7638 & 0,1852 & -0,0724 & 0,1219 \\
-0,1962 & 1,0814 & -0,0200 & -0,7541 \\
-0,5247 & -0,1395 & 0,8603 & -0,1082 \\
-0,6306 & -0,1158 & 0,0027 & 0,6337
\end{array}\right] \\
& A_{2}=\left[\begin{array}{cccc}
-1,1901 & -0,1094 & -0,0249 & 0,0323 \\
-0,1548 & -0,1808 & -0,2012 & 0,7433 \\
0,6967 & -0,1991 & 0,1433 & -0,3899 \\
0,5254 & 0,0922 & 0,0705 & -01024
\end{array}\right]
\end{aligned}
$$




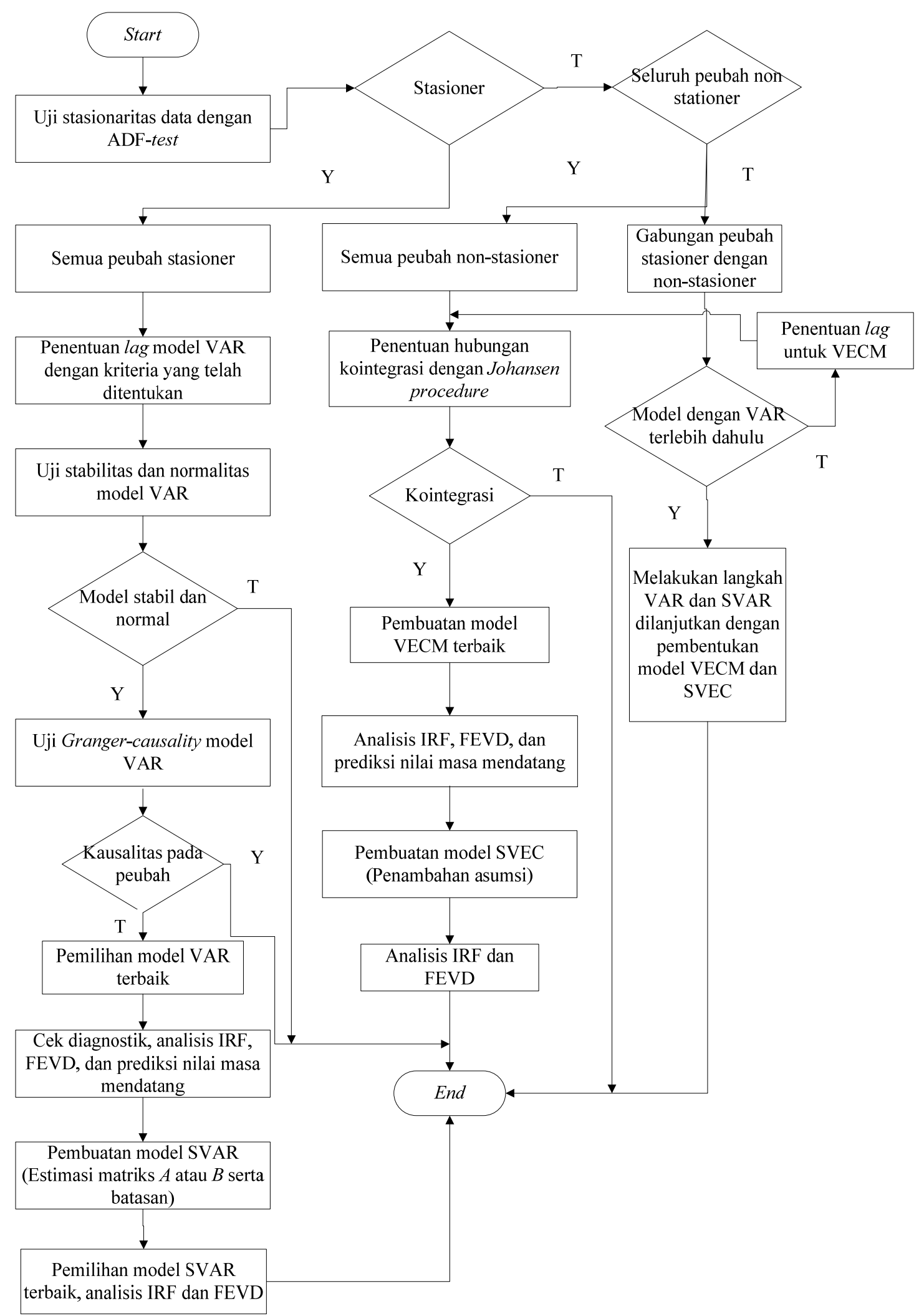

Gambar 1. Flowchart pembuatan model

$A_{3}=\left[\begin{array}{cccc}0,6147 & 0,0256 & 0,0317 & 0,3598 \\ 0,4575 & -0,0205 & 0,1212 & 0,3222 \\ -0,2604 & 0,1416 & 0,2214 & 0,0626 \\ -0,0619 & -0,0285 & -0,0315 & 00455\end{array}\right]$

const $=\left[\begin{array}{c}-193,3704 \\ -13,2192 \\ 192,7772 \\ 163,8897\end{array}\right]$, trend $=\left[\begin{array}{c}-0,0174 \\ 0,0745 \\ 0,0834 \\ 0,0202\end{array}\right]$ 
Gambar 2. Menunjukkan prediksi 5 pekan ke depan dari model VAR.

\section{Analisis SVAR}

Model SVAR yang dibuat adalah berdasarkan $A$ model. Model SVAR membutuhkan batasan sehingga estimasi parameter dapat dilakukan. Empat batasan diberikan secara diagonal untuk matriks model SVAR dari data Canada. Pada versi ini batasan di atas ditanamkan dalam package. Hal ini dimaksudkan agar running program tidak berlebihan baik dalam waktu ataupun space untuk menyimpan setiap matrix yang harus dibangun di dalamnya. Tentunya diperlukan suatu algoritma yang tepat untuk mengatasinya. Masalah ini akan ditindaklanjuti pada penelitian selanjutnya. Dua peubah lainnya yang dijadikan batasan adalah peubah $e$ untuk peubah prod dan peubah $e$ untuk peubah $U$. Tabel 1. memberikan keterangan mengenai hasil dari estimasi model SVAR.

\section{Analisis VECM}

Ketidakstasioneran pada data Canada membuat data tersebut harus dianalisis lebih lanjut menggunakan model VECM. Lag maksimum yang diberikan adalah 10 dan secara otomatis program akan mencari model dengan nilai log-likelihood maksimum. Model terbaik terdapat pada lag 10 dan tipe both. Hasil derajat kointegrasi dengan menggunakan Johansen procedure untuk model terbaik tersebut adalah berderajat 3. Diagnosis untuk model VECM adalah menggunakan histogram, Q-Q plot distribusi normal, ACF, dan PACF dari residual. Semua analisis telah memberikan kesimpulan bahwa model VECM ini layak digunakan untuk meramalkan nilai mendatang. Selanjutnya model VECM ini akan ditransformasikan menjadi model VAR, dan hasil yang diberikan adalah sebagai berikut:
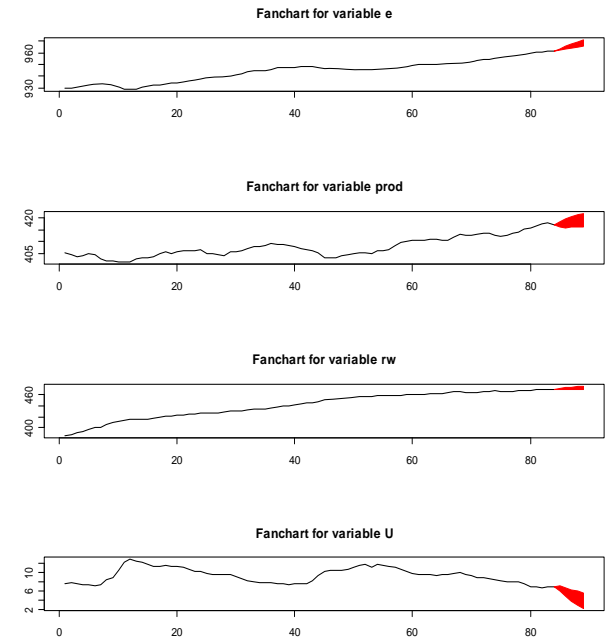

Gambar 2. Peramalan model VAR lima periode
Tabel 1. Nilai Log-Likelihood dan Estimasi Matriks SVAR

\begin{tabular}{|c|c|c|c|c|}
\hline \multicolumn{5}{|c|}{$\begin{array}{l}\text { Estimasi nilai matriks } A \text { model } \\
\text { Nilai log-likelihood: }-175.1474\end{array}$} \\
\hline Peubah & $e$ & prod & $r w$ & $U$ \\
\hline$E$ & 4,3390 & 0,2074 & 0 & 3,8300 \\
\hline Prod & 0 & 1,5906 & 0 & 0 \\
\hline$R w$ & 0 & 0 & 1,3580 & 0 \\
\hline$U$ & 0 & 0 & 0 & 3,5800 \\
\hline
\end{tabular}
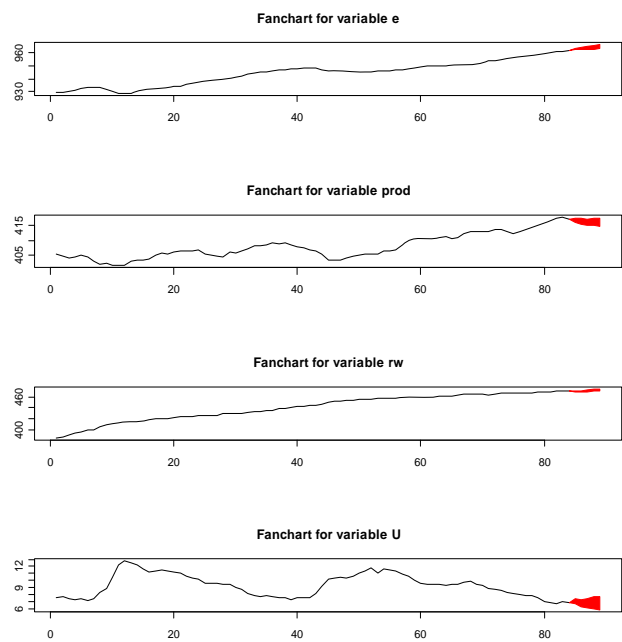

Gambar 3. Peramalan model VECM lima periode

$\left[\begin{array}{c}e_{t} \\ \operatorname{prod}_{t} \\ r w_{t} \\ U_{t}\end{array}\right]=\sum_{i=1}^{10} A_{i}\left[\begin{array}{c}e_{t-i} \\ \operatorname{prod}_{t-i} \\ r w_{t-i} \\ U_{t-i}\end{array}\right]+$ const + trend

Sedangkan prediksi lima pekan mendatang ditunjukkan oleh Gambar 3.

\section{Analisis SVEC}

Peubah-peubah yang menjadi batasan contemporaneous effect adalah:

peubah prod $\rightarrow U$, peubah $e \rightarrow \operatorname{prod}$, peubah $r w \rightarrow$ $U$, peubah $r w \rightarrow$ prod. Hasil dapat dilihat pada Tabel 2 .

Peubah yang menjadi asumsi untuk long-run effect adalah peubah $r w$ dan $U$. Hasil ini dapat dianalisis pada Tabel 3 .

Tabel 2. Hasil SVEC untuk contemporaneous impact

\begin{tabular}{ccccc}
\hline Peubah & $e$ & prod & $r w$ & $U$ \\
\hline$e$ & 0,1813 & 0,0000 & 0,0870 & $-0,1125$ \\
prod & $-0,0770$ & 0,3449 & 0,0333 & 0,0000 \\
$r w$ & $-0,4222$ & 0,0000 & 0,2331 & 0,0000 \\
$U$ & $-0,0725$ & $-0,0103$ & 0,0275 & 0,1630 \\
\hline
\end{tabular}

Tabel 3. Hasil SVEC untuk long-run impact

\begin{tabular}{ccccc}
\hline Peubah & $e$ & prod & $r w$ & $U$ \\
\hline$e$ & 0,6971 & $-0,1498$ & 0,0000 & 0,0000 \\
prod & $-0,2715$ & 0,0584 & 0,0000 & 0,0000 \\
$r w$ & 0,4368 & $-0,0939$ & 0,0000 & 0,0000 \\
$U$ & $-0,2287$ & 0,0492 & 0,0000 & 0,0000 \\
\hline
\end{tabular}




\section{Analisis Impulse Response dan Variance De- composition}

Analisis akan diberikan dari model SVEC. Impulse response dan variance decomposition secara berturut turut dapat dilihat pada Gambar 4 dan Gambar 5 Perubahan sebesar 1 standar deviasi pada peubah prod akan menyebabkan perubahan dengan tren negatif pada enam periode awal ditambah periode sekarang (periode 0). Setelah mengalami tren negatif selama beberapa periode, maka perubahan pada peubah prod akan menyebabkan peubah $U$ mengalami kenaikan dari tren negatif menjadi positif Bermula pada periode ketujuh, kenaikan produktifitas sebaliknya menyebabkan kenaikan pada pengangguran. Jika dilihat secara visual, maka impulse response untuk response peubah prod terhadap peubah $U$ masih dinilai cukup stabil. Hal ini dikarenakan rentang perubahan hanya di antara angka $+/-10 \%$ dan bergerak di garis tengah dari plot impulse response.

Pengaruh peubah $r w$ tidak menunjukkan hasil yang cukup signifikan hingga periode kelima. Kontribusi yang diberikan oleh peubah $r w$ relatif stabil dan hanya berkisar antara 1\%-2,5\%. Kontribusi peubah endogen lainnya yang cukup stabil juga ditunjukkan oleh peubah $e$. Perubahan yang dikarenakan oleh peubah $e$ hanya sekitar 4\%-6\%. Meskipun pengaruh yang diberikan tidak terlalu besar, tetapi peubah $e$ tidak boleh diabaikan.

Pergerakan untuk shock peubah prod memberikan kontribusi terbesar sepanjang periode. Pada periode kedua hingga kelima, nilai perubahan yang diberikan berada pada rentang $75 \%-80 \%$. Adanya hasil sebesar itu yang berasal dari dirinya sendiri akan membuat kesulitan dalam menganalisis seberapa kuat hubungan causality dengan peubah lainnya. Hasil dari variance decomposition untuk menyatakan causality terkuat dapat dimiliki antara peubah prod dengan peubah $U$.

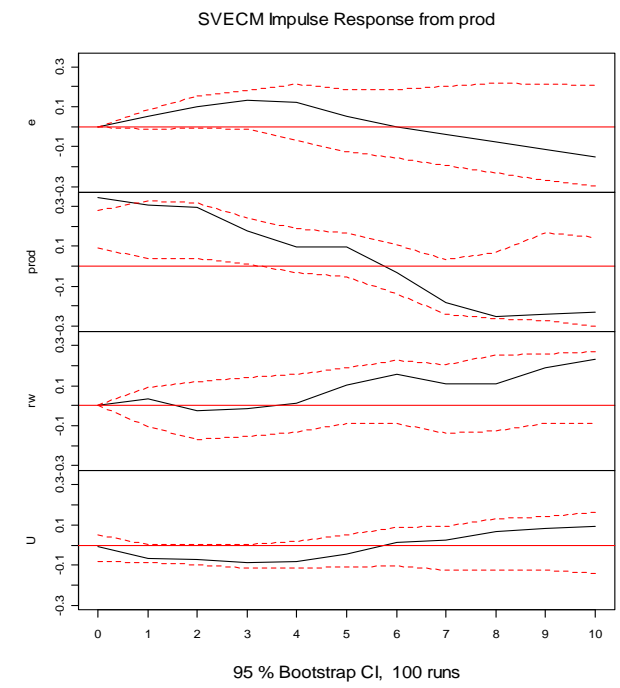

Gambar 4. Impulse response

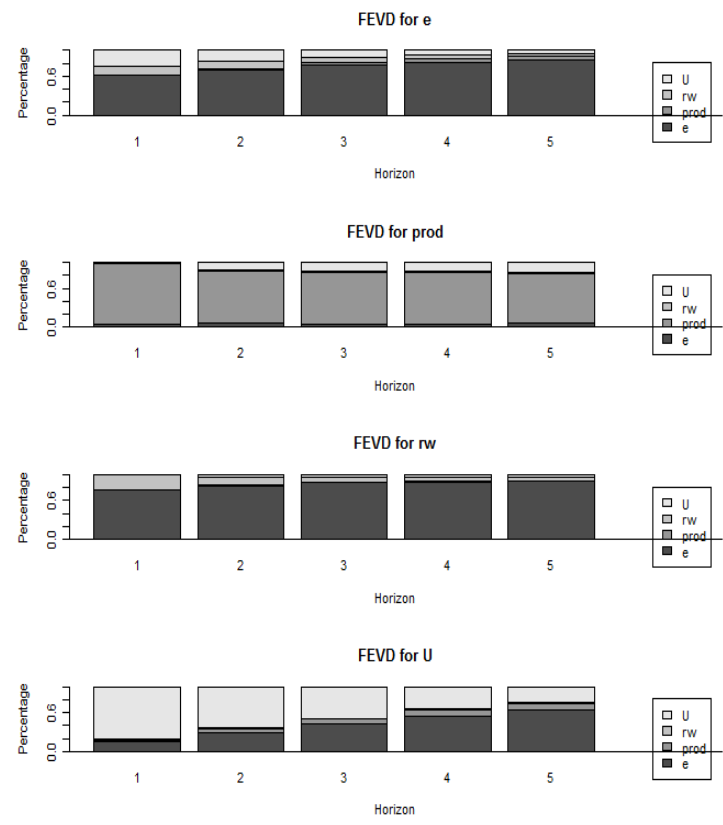

Gambar 5. Variance Decomposition

\section{Simpulan}

Program automatic multivariate dengan software $\mathrm{R}$ telah mampu mengidentifikasi model terbaik untuk data multivariate time series. Model VAR yang digunakan untuk estimasi parameter pada data stasioner dan mencari lag serta tipe karakteristik sudah dapat membangun model secara baik. Model SVAR sebagai pelengkap analisis model VAR memiliki cakupan yang luas sehingga memungkinkan analis melihat kombinasi struktural model berdasarkan kombinasi dan batasan di dalam matriks model.

Model VECM yang dikhususkan untuk data nonstasioner mampu mengestimasi derajat kointegrasi dengan lag dan tipe karakteristik yang tepat. Hasil tersebut akan menjadi unsur dalam transformasi model VECM menjadi model VAR. Analisis inovasi yang ditampilkan pada model SVEC dibuat dengan memperhatikan fleksibilitas dan kemudahan untuk pengguna. Hal ini memungkinkan pengguna untuk melihat hubungan antar peubah dengan asumsi yang dibuat oleh keputusan pengguna sendiri.

Nilai log-likelihood menjadi acuan dalam memilih model terbaik untuk semua model yang ada. Ketepatan dari model yang dipilih juga telah melalui serangkaian uji diagnostik. Prediksi nilai masa mendatang beserta analisis-analisis model dapat menghasilkan evaluasi dan solusi yang mendekati data riil. Namun masih terdapat beberapa hal, seperti batasan pada prediksi season yang hanya diberikan untuk musim 3,6 dan 12; serta batasn lain pada proses automatisasi model SVAR. Keterbatasan ini akan diperbaiki pada package versi selanjutnya. 


\section{Ucapan Terima Kasih}

Penulis mengucapkan terima kasih kepada para penelaah (reviewer) yang telah memberikan masukan hingga naskah ini menjadi lebih baik.

\section{Daftar Pustaka}

1. Akaike, H., Autoregressive model fitting for control, Annals of the Institute of Statistical Mathematics, 23, 1971, pp. 163-180.

2. Brooks, C., Introductory econometrics for finance. New York: Cambridge University Press, 2008.

3. Granger, C.W.J., Some Properties of Time Series Data and Their Use in Econometric Model Specification, Journal of Econometrics, 16, 1981, pp. 121-130.

4. Hadi, Y.S., Analisis Vector Autoregression (VAR) terhadap Korelasi antara Pendapatan
Nasional dan Investasi Pemerintah di Indonesia. Jurnal Keuangan dan Moneter, 6, 2003, pp. 107-121.

5. Halim, S., Bisono, I.N., Melissa, and Cynthia, Automatic Seasonal Auto Regressive Moving Average Models and Unit Root Test Detection, IEEE International conference on Industrial Engineering and Engineering Management proceeding, Singapore 3-5 Dec, 2007, pp. 1129-1133.

6. Harris, R, and Sallis, R., Applied time series modelling and forecasting. New York: John Wiley \& Sons, 2003.

7. Lütkepohl, H., New introduction to multiple time series analysis. Berlin: Springer, 2005

8. Pfaff, B., VAR, SVAR and SVEC models: Implementation within $\mathrm{R}$ package vars. Journal of Statistical Software, 27(4), 2008, pp. 1-29.

9. Sims, C. A., Macroeconomics and reality. Journal Econometrica, 48, 1980, pp. 1-48. 